\title{
Aspectos clínicos relacionados à verticalização de molares
}

Clinical issues concerning molar uprighting

\author{
Fábio Dinamarco Alckmin Maciel ${ }^{*}$ \\ Anderson Paulo Barbosa Lima** \\ Tadeu Evandro Mendes-Júnior ${ }^{* * *}$ \\ Tadeu Evandro Mendes ${ }^{* * *}$ \\ Geraldo Eugênio Marchiori ${ }^{* *+*}$ \\ Luiz Renato Paranhos ${ }^{* * *}$
}

\section{Resumo}

Objetivo: o objetivo do presente artigo é abordar por meio de uma revisão de literatura, aspectos ortodônticos envolvidos na verticalização de molares. Revisão de literatura: a verticalização de molares evita a extrusão excessiva do dente adjacente, prevenindo assim a formação de lesões cariosas. As opções de tratamento para a verticalização dependem do grau de inclinação dos dentes, da posição do dente e do tipo de movimentação desejada. Sendo diagnosticado precocemente, a verticalização pode ocorrer em poucos meses. Considerações finais: a verticalização de molares inclinados é útil e necessária, pois possibilita uma melhora nas condições periodontais dos dentes inclinados, levando a uma diminuição das bolsas infra-ósseas. Com isso, ocorre melhora da topografia óssea e gengival, o que proporciona um melhor acesso para controle de higienização, devolvendo ao indivíduo a saúde dos tecidos de suporte e uma maior longevidade desses.

Palavras-chave: Verticalização dentária. Impactação dentária. Tratamento ortodôntico.

\section{Introdução}

Sistema mastigatório é a unidade funcional do corpo que funciona sob o controle neuromuscular complexo para sua função como mastigar, engolir e falar. O funcionamento adequado faz com que a trituração de alimentos proceda de forma apropriada, resultando, assim, no início do processo digestivo na cavidade oral em si. Durante a sua função, dentes e osso alveolar são constantemente submetidos a forças deletérias. $\mathrm{O}$ organismo fornece o equilíbrio entre raízes e ligamento periodontal para suportar essas forças ${ }^{1}$.

No processo de envelhecimento, alguns dentes são perdidos devido à cárie, à doença periodontal ou por outros motivos, que criam um desequilíbrio, e a integridade do sistema mastigatório é perdida. Quando esses dentes perdidos não são substituídos adequadamente dentro de um intervalo maior, há uma tendência desses migrarem para o espaço vazio numa tentativa de preenchê-lo. $\mathrm{O}$ dente localizado

\footnotetext{
Aluno do curso de especialização em Ortodontia da Inapós - Varginha-MG.

Clínica Privada - São Lourenço-MG.

Clínica Privada - Varginha-MG

Professor do Curso de Especialização em Ortodontia da Inapós - Varginha-MG

Professor do Curso de Especialização em Ortodontia da Inapós - Varginha-MG.

* Professor adjunto da Universidade Federal de Sergipe - Lagarto-SE.
} 
distalmente ao local de extração migra mesialmente ${ }^{2}$. Associado à inclinação mesial, acompanham os defeitos intraósseos verticais e bolsas infraósseas na região mesial dos molares, a migração distal dos pré-molares, extrusão do molar antagonista, contatos prematuros em relação cêntrica, interferências oclusais nos movimentos de lateralidade e protusão, além de dificultar a confecção de próteses, quando a inclinação é excessiva ${ }^{3}$.

Outra causa comum de falta de espaço para erupção é quando a sequência de erupção não é considerada como favorável. Essa sequência de erupção favorável para obtenção de oclusão normal no arco dental maxilar, para a dentição permanente é a seguinte: primeiro molar, incisivo central, incisivo lateral, primeiro pré-molar, segundo pré-molar, canino, segundo molar e terceiro molar ${ }^{4}$.

Esse resultado, em dispersão de tensões em torno dos vértices dos dentes no osso alveolar é bem diferente dos padrões de tensões produzidas no osso alveolar por dentes normais. Como resultado da inclinação dos dentes, tensões são concentradas em algumas áreas que conduzem à reabsorção do osso na área de apoio, causando enfraquecimento do ligamento periodontal dos dentes. Alterações nas angulações dos dentes no local da extração é um problema comum que afeta a oclusão $0^{5}$.

A inclinação de molares pode ainda ocorrer devido à existência de elementos dentais anquilosados que se encontram em estado grave de infra-oclusão, quando existe ocorrência de irrupção ectópica de molares ou pelo uso prolongado de aparelho extrabucal $^{6}$.

A verticalização do molar para a sua correta posição leva à normalização da situação oclusal funcional e periodontal, permitindo o alinhamento das raízes perpendiculares ao plano oclusal, de forma que resista melhor às forças oclusais. Ela é uma terapia ortodôntica muito utilizada em adultos, em conjunto com a terapia periodontal restauradora, buscando importantes benefícios, como o paralelismo dos dentes que servirão de apoio para próteses fixas ou removíveis, obtenção de um espaço edêntulo adequado e a eliminação ou a redução dos defeitos ósseos verticais ${ }^{7}$.

Com base no exposto, o objetivo do presente artigo é, por meio de uma revisão da literatura, abordar aspectos ortodônticos envolvidos na verticalização de molares, sempre buscando excelência nos tratamentos ortodônticos.

\section{Revisão de literatura}

A impactação de dentes permanentes geralmente envolve os terceiros molares superiores ou inferiores, caninos superiores ou incisivos centrais, e segundo pré-molares inferiores ${ }^{8}$. Distúrbios de erupção dos segundos molares permanentes mandibulares são bastante raros. Estudos mostram taxas de $0,03 \%$ a $0,04 \%^{9}$ da incidência de impactação do segundo molar em radiografias panorâmicas. A etiologia da impactação pode estar relacionada a algum distúrbio de crescimento mandibular fisiológico e de desenvolvimento do dente. O espaço para os segundos molares permanentes é obtido pela reabsorção do osso na borda anterior do ramo mandibular e a migração mesial do primeiro molar para o espaço livre. O germe dental do segundo molar permanente desenvolve-se com inclinação mesio-axial, e a capacidade para autocorreção natural ocorre durante o processo de remodelação ${ }^{9}$.

Desequilíbrios nesse processo natural podem levar à impactação e estarem associados a um arco com comprimento deficiente em função do crescimento mandibular inadequado. $\mathrm{O}$ excesso de espaço entre $\mathrm{o}$ desenvolvimento do segundo molar e primeiro molar também pode resultar em impactação, provavelmente porque a coroa do segundo molar necessita da raiz distal do primeiro molar para erupcionar. Dentre os fatores iatrogênicos importantes, inclui-se uma banda mal encaixada (cimentada) no primeiro molar inferior, prévia expansão sagital ortodôntica ${ }^{5,10}$, e prevenção da mesialização do primeiro molar permanente causada pela placa lábio ativa ou pela terapia de arco lingual. Às vezes o segundo molar fica impactado de forma espontânea, o que está provavelmente relacionado com a posição do terceiro molar ${ }^{11}$.

$\mathrm{Fu}$ et al. ${ }^{12}$ (2012) verificaram a prevalência e a severidade do segundo molar inferior permanente impactado (SMIPI) numa população tailandesa, bem como o tratamento utilizado para os SMIPI. Foram identificados 96 pacientes com 125 SMIPI que receberam tratamento ortodôntico de um universo de 21.580 pacientes. A prevalência de SMIPI foi de $0,65 \%$. A média inicial de verticalização foi de 3,6 meses e não houve diferença entre gênero, idade, angulação e profundidade. Embora as impactações sejam raras, os autores recomendam o diagnóstico precoce para que o tratamento seja melhor e com um menor tempo.

A verticalização de molar impactado e a sua extrusão tem algumas vantagens funcionais periodontais e restauradoras. A verticalização de segundo molar permite evitar um encurtamento do plano oclusal que pode resultar da perda de dentes impactados, especialmente em casos de imprevisibilidade da posição do terceiro molar. Além disso, os dentes sem antagonistas têm uma tendência a entrarem em erupção excessivamente. $\mathrm{O}$ benefício periodontal da verticalização dos molares é a eliminação de falsas bolsas periodontais, o que facilita o controle de placa na área ${ }^{8}$. Uma vez que a higiene oral adequada na área de dentes impactados é difícil, podem surgir facilmente lesões de cárie no dente não erupcionado. A verticalização de molares impactados, portanto, parece benéfica na prevenção da cárie. Um segundo molar impactado não diagnosticado precocemente pode danificar a raiz distal do primeiro molar. 
A melhor época para realizar uma abordagem ortodôntica no segundo molar inferior impactado é entre 11 e 14 anos de idade, quando o desenvolvimento das raízes dos segundos molares permanentes ainda é incompleto. As opções de tratamento dependem do grau de inclinação do dente. A inclinação mais grave requer métodos cirúrgicos ou de erupção assistida ortodonticamente. Os métodos cirúrgicos incluem reposicionamento cirúrgico com ou sem extração do terceiro molar, ${ }^{11}$ podendo ser a com extração do segundo molar impactado para permitir a erupção do terceiro molar ou com o transplante do terceiro molar ao espaço do segundo molar ${ }^{13}$. Os benefícios específicos para o ganho dependem da direção que o molar se move em ambos os planos de espaço vertical e mesiodistal.

No plano mesiodistal, o molar pode ser desviado para o lado distal ou a raiz do molar pode ser movida para o plano mesial. Uma vez que o segundo molar é mais comumente encontrado quando um primeiro molar está faltando, o movimento mesial da raiz do segundo molar é, geralmente, seguido pelo movimento de todo o dente para fechar o espaço. A inclinação distal é a solução mais comum nessa situação, devido aos problemas que podem ser encontrados com movimentação mesial se o osso alveolar diminui na região do primeiro molar perdido. Esses problemas podem incluir reabsorção radicular, deiscência óssea e uma diminuição da taxa de movimento ${ }^{8}$.

As vantagens periodontais de verticalização dos dentes incluem a eliminação de falsas bolsas periodontais que frequentemente se formam na face mesial desses dentes. A eliminação da falsa bolsa periodontal pode melhorar a capacidade do paciente de controlar a placa na região. As vantagens protéticas de verticalização do molar via inclinação distal incluem uma melhor linha de desenho no caso de confecção de uma ponte ou de aumento do espaço se uma prótese implanto-suportada é planejada. As vantagens funcionais da verticalização de um molar por reposicionamento da coroa na face distal incluem a promoção de contato oclusal para cada dente no arco oposto. Os dentes sem oclusão podem levar a uma erupção excessiva ${ }^{8}$.

Girwlli et al. ${ }^{5}$ (2010) relatam um caso de um paciente de 28 anos que apresentava má oclusão de Angle Classe II, subdivisão esquerda, com desvio da linha média inferior para a esquerda. Os dentes 37 , 38, 47 e 48 apresentavam-se inclinados mesialmente. Foram utilizadas molas T simples e dupla, o que permitiu a rotação com movimento mesial de raiz, além de leve força extrusiva na mesial dos molares inclinados. Os autores finalizam salientando a importância da verticalização dos molares inclinados, pois possibilita melhores condições periodontais dos dentes inclinados, com redução da formação de bolsas periodontais infraósseas.

No plano vertical, o molar pode ser extruído, intruído ou sua posição vertical pode ser mantida. É importante notar que há alguma variabilidade nas respostas dos pacientes às forças ortodônticas. Por exemplo, dois pacientes poderiam ter forças extrusivas da mesma magnitude colocadas nos seus molares, e um poderia ter uma extrusão significativa, enquanto o outro não. Essa variabilidade pode ser causada pela magnitude e pela duração de forças exercida pelo paciente que se opõem à força de extrusão. Uma vez que a resposta a essas forças é pouco imprevisível, o cirurgião-dentista que irá determinar a direção que ele gostaria que o dente se movesse, bem como o plano de força ${ }^{9}$.

Quando um molar é extruído na presença de um dente oposto podem ocorrer dois fatos: os dentes entram em contato prematuro no início do fechamento da mandíbula, surgindo, assim, a mordida aberta anterior, ou a superfície oclusal de um ou de ambos os dentes opostos está reduzida ${ }^{14}$.

Reduzir a superfície oclusal de um dente pode ter efeitos benéficos, incluindo a redução da proporção coroa-raiz. Uma redução significativa do dente também poderia ter efeitos negativos, tais como a sensibilidade pulpar, a exposição pulpar e a redução da altura da coroa para construção de pontes. Outra potencial vantagem da extrusão, particularmente para pacientes que têm doença periodontal na forma de perda de inserção, é uma redução da profundidade de bolsa, não apenas na mesial, mas também para o resto do dente ${ }^{3,15}$.

A manutenção da posição vertical do dente, uma vez que ele foi verticalizado, não significa que a posição vertical da coroa será mantida. $O$ dente pode girar em torno do seu centro de resistência, e o centro de resistência não se move no plano oclusal, a coroa poderá se mover oclusalmente, embora, não tanto quanto se o dente estivesse extruído ${ }^{8}$.

A intrusão do molar quando está sendo verticalizado pode ser vantajosa, se o cirurgião-dentista deseja evitar a abertura da mordida anterior. Isso é particularmente aplicável se um implante for utilizado para substituir a prótese de um dente perdido. Nessa situação, o segundo molar não será utilizado como um pilar da ponte e a redução do esmalte pode ser minimizada ${ }^{8}$.

Os riscos da intrusão de um molar incluem a possibilidade de criar uma bolsa periodontal infraóssea, uma vez que a placa supragengival pode ser deslocada para um local subgengival. Obviamente, o movimento oclusal dos dentes anteriores poderia reduzir a profundidade de trespasse ${ }^{8}$.

A mola helicoidal de verticalização é o aparelho mais utilizado para verticalização molar. Esse aparelho verticaliza o molar com deslocamento distal da coroa e extrusão do molar. A mola helicoidal de verticalização, como muitas outras aplicações ortodônticas utiliza um fio elasticamente deformado para exercer forças sobre os dentes. Com esse aparelho, é inserido um fio ativo para o suporte o fato de que está afixado ao molar mesialisado. Normalmente, esse fio ativo é relativamente grande e retangular - para que não haja espaço para o fio rodar 
ou mover no interior do braquete de suporte. Claro que, se o fio fosse suficientemente pequeno para girar dentro do suporte, o fio poderia girar para uma posição a partir da qual ele iria produzir sentidos alterados da força e um indesejável movimento do dente poderia ocorrer ${ }^{4}$.

Reddy et al. ${ }^{4}$ (2008) relatam um caso de verticalização de molar utilizando a mola helicoidal. Uma criança de 12 anos exibia o segundo molar inferior direito mesializado. $\mathrm{O}$ aparelho foi ativado a cada duas semanas e dentro de dois meses o dente estava verticalizado.

Um dos mais fáceis e mais confiáveis meios para determinar todas as forças que um aparelho vai exercer sobre os dentes é estabelecer todas as forças que são necessárias para ativar ou deformar elasticamente o aparelho. Para deformar a mola, um conjunto equilibrado de forças deve ser colocado sobre ela. Se as forças não estão equilibradas, o fio não irá deformar, mas vai mover-se para uma nova posição. Para demonstrar a natureza equilibrada das forças que são necessárias para deformar o fio, serão descritas a seguir as forças que atuam sobre o fio ${ }^{8}$.

A força mais evidente que atua sobre o fio depois que foi colocado no braquete do molar é a força oclusalmente dirigida que levanta o gancho para que ele possa ser colocado sobre o fio anterior. No entanto, se essa fosse somente a força que atua sobre o fio, ele não deformaria. Ele simplesmente se moveria na direção oclusal. O braquete do molar prende o fio e o impede de se mover oclusalmente, exercendo uma força dirigida apicalmente sobre ele. No entanto, se essas duas forças fossem as únicas que atuassem no fio, ainda não iria deformar elasticamente, mas simplesmente rotacionar ${ }^{3}$.

À medida que o fio começa rodar em um sentido anti-horário, ele encontra a face mesial e distal do braquete do molar. A face mesial do braquete exerce uma força dirigida apicalmente no fio, e a face distal exerce uma força dirigida para a coroa sobre o fio. As forças combinadas identificadas, até agora, irão deformar a mola. A razão pela qual o fio agora deforma é porque uma força adversária (ou equilíbrio) ou conjunto de forças bloqueia cada movimento do fio. Uma vez que o fio é maleável, a deformação é elástica. Visto que essa mola é elasticamente deformada, ela vai exercer forças sobre a que mantém para não deformá-la. Quando o fio é ligado aos dentes, ele vai exercer forças sobre esses dentes. Essas forças são opostas na direção das forças que agem sobre o fio para deformá-lo. Uma força intrusiva atua sobre os dentes anteriores e forças extrusivas sobre os molares e, também há duas forças que são paralelas, mas não colineares, que atuam no braquete do molar, girando-o distalmente ${ }^{8}$.

Kojima et al. ${ }^{2}$ (2009) avaliaram o efeito da extração do segundo molar superior na morfologia dentofacial ante e após o tratamento da mordida aberta. Trinta pacientes foram divididos em dois grupos: os que tiveram o elemento dental removido e os que foram tratados sem extração. Cefalogramas laterais foram feitas antes e após o tratamento. Os que tiveram o dente extraído exibiram maior extrusão dos incisivos superiores e movimentação distal dos primeiros molares superiores. Houve maior intrusão dos molares superiores no primeiro grupo e uma extrusão não significativa dos molares superiores do segundo grupo.

Kenrad et al. ${ }^{16}$ (2011) realizaram um estudo retrospectivo da escolha de tratamento para dentes intruídos. Dos 126 pacientes estudados, a maioria (48\% aproximadamente) foi tratada com a remoção cirúrgica do terceiro e/ou do segundo molar. Apenas sete pacientes foram tratados com a verticalização dos molares. Os autores comentam que é inaceitável o tratamento mais agressivo (remoção do elemento dental), considerando que existem novos métodos ortodônticos para esse tipo de abordagem.

Em consonância com o caso anterior, Lau et al. ${ }^{1}$ (2013) relatam um caso de uma criança de nove anos de idade, a qual apresentava os segundos molares superiores e inferiores severamente impactados e, ainda assim, tiveram os dentes verticalizados pelas técnicas ortodônticas.

\section{Discussão}

No dia a dia da prática da clínica da ortodontia, encontram-se molares inclinados mesialmente associados às perdas e inclinações dos dentes posteriores, aos defeitos infraósseos verticais na região mesial dos molares, à migração distal dos pré-molares, à extrusão do molar antagonista, aos contatos prematuros, às interferências oclusais nos movimentos de lateroprotusão, impactação, além de dificuldades na adaptação de próteses, quando a inclinação é excessiva. A impactação é algo não muito comum conforme observado no estudo de Fu et al. ${ }^{12}$ (2012).

A verticalização de molares é uma terapia ortodôntica muito utilizada em adultos, em conjunto com a terapia periodontal restauradora, buscando importantes benefícios, tais como: paralelismo dos dentes que servirão de apoio para próteses fixas ou removíveis, obtenção de um espaço edêntulo adequado e eliminação ou redução dos defeitos ósseos verticais. Fu et al. ${ }^{12}$ (2012) observaram um tempo médio de 3,6 meses para ocorrer a verticalização, semelhante ao caso relatado por Reddy et al. ${ }^{4}$ (2008) em que a movimentação durou dois meses. Caso o diagnóstico seja precoce, o tratamento pode ocorrer em um menor intervalo de tempo.

A remoção cirúrgica de dentes inclinados, apinhados, entre outros, já foi muito utilizada no passado, conforme constatado no estudo de Kenrad et al. ${ }^{16}$ (2011), pois verificaram que $48 \%$ dos pacientes foram tratados com a remoção cirúrgica do terceiro e/ou segundo molar, e, apenas sete pacientes foram tratados com a verticalização dos molares.

Atualmente, a verticalização é uma alternativa mais conservadora. Os métodos mais comuns 
de verticalização ortodôntica utilizam-se de molas soldadas nos arcos contínuos, nas bandas ou também em aparelhos removíveis. Kojima et al. ${ }^{2}$ (2009) reforçam esse aspecto em seu estudo ao verificar que aqueles pacientes que tiveram os elementos dentais removidos cirurgicamente exibiram maior extrusão dos incisivos superiores e movimentação distal dos primeiros molares superiores, quando comparados aos pacientes tratados com a verticalização.

Cada paciente deve ser estudado com muito cuidado para propiciar um desenho individualizado da mola, permitindo uma abordagem segura e correta do problema em relação à quantidade e à direção de força aplicada, evitando traumas na mucosa e facilitando higienização da área. Girelli et al. ${ }^{5}$ (2010) pontuam isso em um relato, pois verificaram que com a verticalização houve melhores condições periodontais dos dentes inclinados, com redução da formação de bolsas periodontais infraósseas.

O tratamento deve ser acompanhado com cuidado e a possível ocorrência de uma interferência oclusal, causada por uma extrusão excessiva, deve ser constantemente observada e eliminada ${ }^{15}$.

\section{Considerações finais}

A verticalização de molares inclinados é útil e necessária, pois possibilita uma melhora das condições periodontais dos dentes inclinados, levando a uma diminuição das bolsas infraósseas. Com isso, ocorre a melhora da topografia óssea e gengival, o que proporciona um melhor acesso ao controle de higienização, devolvendo ao indivíduo saúde dos tecidos de suporte e uma maior longevidade desses. Caso o diagnóstico seja precoce, o tratamento pode ocorrer em um menor intervalo de tempo.

\section{Abstract}

Objective: This paper aims to review the literature addressing orthodontic issues implicated in molar uprighting. Literature review: Molar uprighting prevents excessive extrusion of the adjacent tooth, thus hindering the onset of dental caries. The uprighting treatment options depend on the degree of teeth inclination and position and on the type of movement desired. If diagnosis is early established, uprighting can occur in a few months. Final considerations: The uprighting of tilted molars is useful and necessary, as it allows an improvement in their periodontal condition, leading to a decrease of infra-bony pockets. As a result, there is an improvement in bone and gingival topography which provides better access to hygiene control, as well as health and greater longevity of supporting tissues.

Keywords: Teeth uprighting. Tooth impaction. Orthodontic treatment.

\section{Referências}

1. Lau CK, Whang CZ, Bister D. Orthodontic uprighting of severely impacted mandibular second molars. Am J Orthod Dentofacial Orthop 2013; 143(1):116-24.

2. Kojima K, Endo T, Shimooka S. Effects of maxillary second molar extraction on dentofacial morphology before and after anterior open-bite treatment: a cephalometric study. Odontology 2009; 97(1):43-50.

3. Rao J, Singh GK, Alvi HA, Kumar L, Agrawal KK. Removable partial denture with molar uprighting spring: an innovative hybrid appliance. J Prosthodont 2013; 57(1):57-61.

4. Reddy SK, Uloopi KS, Vinay C, Subba Reddy VV. Orthodontic uprighting of impacted mandibular permanent second molar: a case report. J Indian Soc Pedod Prev Dent 2008; 26(1):29-31.

5. Girelli VCB, Santos GL, Nogueira FF, Penido SMM. Verticalização de molares inferiores: revisão de literatura e relato de caso clínico. Rev Clín de Ortodon Dental Press 2010; $9(2): 67-76$

6. Freitas JR, Ramalho SA, Vedovello Filho M, Vedovello SAS. Verticalização dos segundos molares inferiores. J Bras Ortodont Ortoped Facial 2002; 6(36):449-56.

7. Miranda FM, Pacheco F, Ruellas ACDO. Tratamento ortodôntico para verticalização de molar superior permanente. Rev Univ Alfenas 1999; 5:251-3.

8. Shellhart WC, Oesterle LJ. Uprighting molars without extrusion. J Am Dent Assoc 1999; 130(3):381-5.

9. Majourau A, Norton LA. Uprighting impacted second molars with segmented springs. Am J Orthod Dentofacial Orthop 1995; 107(3):235-8.

10. Eckhart JE. Orthodontic uprighting of horizontally impacted mandibular second molars. J Clin Orthod 1998; 32(10):621-4.

11. McAboy CP, Grumet JT, Siegel EB, Iacopino AM. Surgical uprighting and repositioning of severely impacted mandibular second molars. Am Dent Assoc 2003; 134(11):1459-62.

12. Fu PS, Wang JC, Wu YM, Huang TK, Chen WC, Tseng YC, et al. Impacted mandibular second molars. Angle Orthod 2012; 82(4):670-5.

13. Orton-Gibbs S, Crow V, Orton HS. Eruption of third permanent molars after the extraction of second permanent molars. Part 1: Assessment of third molar position and size. Am J Orthod Dentofacial Orthop 2001; 119(3):226-38.

14. Sawicka M, Racka-Pilszak B, Rosnowska-Mazurkiewicz A. Uprighting partially impacted permanent second molars. Angle Orthod 2007; 77(1):148-54.

15. McAboy CP, Grumet JT, Siegel EB, Iacopino AM. Surgical uprighting and repositioning of severely impacted mandibular second molars. J Am Dent Assoc 2003; 134(11):1459-62.

16. Kenrad J, Vedtofte H, Andreasen JO, Kvetny MJ, Kjaer I. A retrospective overview of treatment choice and outcome in 126 cases with arrested eruption of mandibular second molars. Clin Oral Investig 2011; 15(1):81-7.

\section{Endereço para correspondência:}

Luiz Renato Paranhos

Residencial Vista do Atlântico, ap. 1402

Rua Jordão de Oliveira, 996, Bairro Atalaia.

49037-330 Aracaju-SE

Fone: (79) 9116-1896

E-mail: paranhos@ortodontista.com.br

Recebido: 20/05/2014. Aceito: 21/07/2014. 